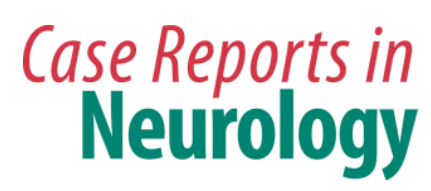

Case Rep Neurol 2014;6:14-17

\title{
Caudal Cingulate Infarction Manifesting Astasia
}

\author{
Takeshi Satow Taro Komuro Akira Kobayashi \\ Department of Neurosurgery, Nagahama City Hospital, Nagahama, Japan
}

\section{Key Words}

Astasia $\cdot$ Stroke $\cdot$ Cingulate motor area

\begin{abstract}
Introduction: Astasia is a rare presenting symptom of stroke, usually known as 'thalamic astasia', induced by a lesion in the ventrolateral thalamus. We report a case of caudal cingulate infarction manifesting astasia. Case Presentation: A 58-year-old male presented with inability to sit, stand and walk (astasia). No apparent motor weakness was noticed in the extremities. MRI revealed cerebral infarction in the caudal cingulate gyrus, which was located between the vertical commissure anterior (VCA) line and vertical commissure posterior (VPC) line. His symptoms persisted for 1 year to a lesser degree. Conclusion: Lesions in the caudal cingulate gyrus can present with astasia. The responsible lesion is located in the cingulate gyrus between the VCA and VPC line, which might correspond to the caudal cingulate zone in humans. We should keep in mind that astasia can be a presenting symptom of stroke.
\end{abstract}

(C) 2014 S. Karger AG, Basel

\section{Introduction}

Astasia is a condition of inability to stand without apparent motor weakness. This rare symptom has been reported in association with stroke involving the thalamus [1-3], mesencephalon [4] or the pontomesencephalic locomotor region [5]. Apart from the lesion of the above-mentioned deep structures, the involvement of the cerebral cortex is rarely reported in association with astasia. Only one case of cingulate infarction manifesting astasia was reported [6]. This article reports a second case of caudal cingulate infarction manifesting astasia. We will discuss possible mechanisms causing astasia due to cingulate lesions. 


\section{Case Report}

A 58-year-old male with a history of hypertension and diabetes mellitus presented to our emergency room. He complained of dysarthria and inability to sit, stand and walk since his awakening. On admission, he was alert and oriented. He was slightly dysarthric. His MiniMental State Examination score was 30. He showed neither hemispatial neglect nor disconnection syndrome. Muscle strength of all extremities and the trunk was not decreased. On sensory examination, vibratory sensation was slightly decreased on both feet, which was attributed to diabetes mellitus. Thermal, pinprick and positional sensation was perceived normally in all extremities and trunk. The finger-to-nose test revealed terminal dysmetria in the right arm. However, the heel-to-shin test showed no asymmetry. Rapid alternating hand movement was not disturbed on both sides. Deep tendon reflexes were normoactive without pathological reflexes. He did not show any resting or intentional tremor nor asterixis. When he attempted to sit, he grasped the bed rails only with both hands to pull himself up without using his axial and leg muscles, but retropulsion occurred soon after detaching his hands from the bed rails. When tested lying on the bed, he could maintain his legs elevated for more than $10 \mathrm{~s}$. However, he could not stand by himself unless his caregiver supported him.

CT of the brain did not show any intracranial hemorrhage. Then, an MRI of the brain was performed and diffusion-weighted imaging showed a high-intensity lesion at the medial frontal lobe on the left side (fig. 1a). A sagittal section of the double inversion recovery sequence revealed a high-intensity lesion at the cingulate gyrus between the VCA and VCP line and a corpus callosum body (fig. 1b).

After 3 weeks of rehabilitation, he could keep standing and walk freely without assistance. His gait was not broad-based and the steps were regular in amplitude and direction. However, when standing on one foot and walking in tandem gait, lateropulsion to the right side persisted. With his eyes closed, lateropulsion to the right remained. After discharge, he could return to work, although the slight lateropulsion on tandem gait and standing on one foot persisted even at 1 year after onset.

\section{Discussion}

In this case report, we showed that a posterior cingulate infarction can present with astasia. In our patient, the responsible lesion for this symptom was located in the cingulate gyrus between the VCA and VCP line.

Astasia is defined as the inability to stand with minimal sensorimotor deficits. Astasia is usually associated with abasia (inability to walk) in patients with central nervous diseases. However, patients with peripheral neuropathy may experience a period when they are able to walk but are unable to stand still, which is called astasia without abasia [7]. Astasia-abasia was first reported by Blocq [8], after which it was considered as a hysterical disease. Masdeu and Gorelick [1] first systematically described 15 patients with astasia caused by unilateral thalamic lesion (also called 'thalamic astasia'). The mesencephalon [4] or the pontomesencephalic locomotor region [5] was also reported as a responsible lesion for astasia. In patients with the so-called 'thalamic astasia,' the superior portion of the ventrolateral nucleus (VL) of the thalamus was mainly involved. Unlike in the present case, patients had transient symptoms and patients with 'thalamic astasia' had a variable degree of sensory loss [1]. The mechanism of thalamic astasia was explained, at least partly, by disruption of the fastigial fibers of the vestibulocerebellar pathway, which projects to the posterior portion of VL to the thalamus and/or projects fibers from the superolateral part of VL to the 
Satow et al.: Caudal Cingulate Infarction Manifesting Astasia

medial part of the primary motor area [1]. In patients with stroke in the pontomesencephalic locomotor area, astasia was considered to be due to impairment of fastigial efferent fibers in the pedunculopontine area [5].

Kataoka et al. [6] reported a similar case of posterior cingulate infarction manifesting astasia. They postulated that the disruption of connection between the cingulate motor area and the vestibulocerebellar system through the thalamus might be responsible for astasia. Sagittal plane MRI was not shown in their report. The present case is the first to show the location of the lesion manifesting astasia in relation to the VCA and VCP line. Additionally, the astasia and lateropulsion in Kataoka et al.'s [6] report subsided at 1 month. However, in our case, the patient's symptoms persisted for a follow-up period of 1 year.

The role of the cingulate cortex on gait (or maintaining an upright position) is rarely studied in normal subjects. Hanakawa et al. [9] in their SPECT study showed that gait increased activity in multiple cortical motor areas including the cingulate motor area. Wang et al. [10] in their fMRI study also reported that gait increased activity in the cingulate cortex in normal subjects. Projections from the primary motor area, the lateral premotor cortex, supplementary motor area, and the cingulate cortex to the brain stem reticular formation may provide parallel inputs to maintain gait $[11,12]$. Astasia caused by supplementary motor area infarction [13] might be explained by disruption of parallel input from primary and/or non-primary motor cortices to the brain stem gait center.

In humans, the precise location of the cingulate motor area remains to be elucidated. In the macaque monkey, three cingulate motor areas were identified: the rostral cingulate motor area (CMAr), the caudal cingulate motor area in the ventral bank of the sulcus (CMAv), and the caudal cingulate motor area in the dorsal bank of the sulcus (CMAd). Picard and Strick [14] have proposed that corresponding areas are also present in humans: a rostral cingulate zone (RCZ) with two subdivisions (anterior: RCZa, posterior: RCZp) and a caudal cingulate zone (CCZ). The infarcted lesion in the present patient might correspond to CCZ. CCZ is activated not only by simple motor tasks but also by somatosensory stimulation [15]. Representation of somatosensory processing in CCZ might explain the astasia, namely imbalance of upright posture, which might have caused gait disturbance in the present patient.

\section{Conclusion}

Caudal cingulate motor infarction in humans may present with astasia. Even though astasia is a very rare symptom, we should keep in mind that it can be a presenting symptom of stroke.

\section{Acknowledgment}

The authors thank T. Miyagawa, radiological technician, for his enthusiastic efforts to maintain quality of MRI in the Nagahama City Hospital.

\section{Disclosure Statement}

The authors have no conflicts of interest to disclose. 


\section{Case Reports in Neurology}

\begin{tabular}{l|l}
\hline Case Rep Neurol 2014;6:14-17 \\
\hline DOI: $10.1159 / 000358047$ & $\begin{array}{l}\text { C 2014 S. Karger AG, Basel } \\
\text { www.karger.com/crn }\end{array}$ \\
\hline
\end{tabular}

Satow et al.: Caudal Cingulate Infarction Manifesting Astasia

\section{References}

1 Masdeu JC, Gorelick PB: Thalamic astasia: inability to stand after unilateral thalamic lesions. Ann Neurol 1988;23:596-603.

2 Elwischger K, Rommer P, Prayer D, Mueller C, Auff E, Wiest G: Thalamic astasia from isolated centromedian thalamic infarction. Neurology 2012;78:146-147.

- Lee PH, Lee JH, Joo US: Thalamic infarct presenting with thalamic astasia. Eur J Neurol 2005;12:317-319.

-4 Song IU, Kim JS, An JY, Kim YI, Lee KS: Co-occurrence of astasia and unilateral asterixis caused by acute mesencephalic infarction. Eur Neurol 2007;57:106-108.

5 Masdeu JC, Alampur U, Cavaliere R, Tavoulareas G: Astasia and gait failure with damage of the pontomesencephalic locomotor region. Ann Neurol 1994;35:619-621.

-6 Kataoka H, Sugie K, Kohara N, Ueno S: Novel representation of astasia associated with posterior cingulate infarction. Stroke 2006;37:e3-e5.

7 Hirayama K, Nakajima M, Kawamura M, Koguchi Y: Astasia without abasia due to peripheral neuropathy. Arch Neurol 1994;51:813-816.

8 Blocq P: Sur une affection caractérisée par de l'astasie et de l'abasie. Arch Neurol (Paris) 1888;15:24-51, 187-211.

-9 Hanakawa T, Katsumi Y, Fukuyama H, Honda M, Hayashi T, Kimura J, Shibasaki H: Mechanisms underlying gait disturbance in Parkinson's disease: a single photon emission computed tomography study. Brain 1999;122:1271-1282.

10 Wang C, Wai Y, Kuo B, Yeh YY, Wang J: Cortical control of gait in healthy humans: an fMRI study. J Neural Transm 2008;115:1149-1158.

11 Kuypers HG, Lawrence DG: Cortical projections to the red nucleus and the brain stem in the Rhesus monkey. Brain Res 1967;4:151-188.

12 Nutt JG, Marsden CD, Thompson PD: Human walking and higher level gait disorders, particularly in the elderly. Neurology 1993;43:268-279. Comment in: Neurology 1994:44:779-780.

13 Wada Y, Nishimura Y: Isolated astasia in acute infarction of the supplementary-motor area. BMJ Case Rep 2010, DOI: 10.1136/bcr.01.2010.2618.

14 Picard N, Strick PL: Medial wall motor areas: a review of their location and functional activation. Cereb Cortex 1996;6:342-353.

15 Coghill RC, Talbot JD, Evans AC, Meyer E, Gjedde A, Bushnell MC, Duncan GH: Distributed processing of pain and vibration by the human brain. J Neurosci 1994;14:4095-4108.

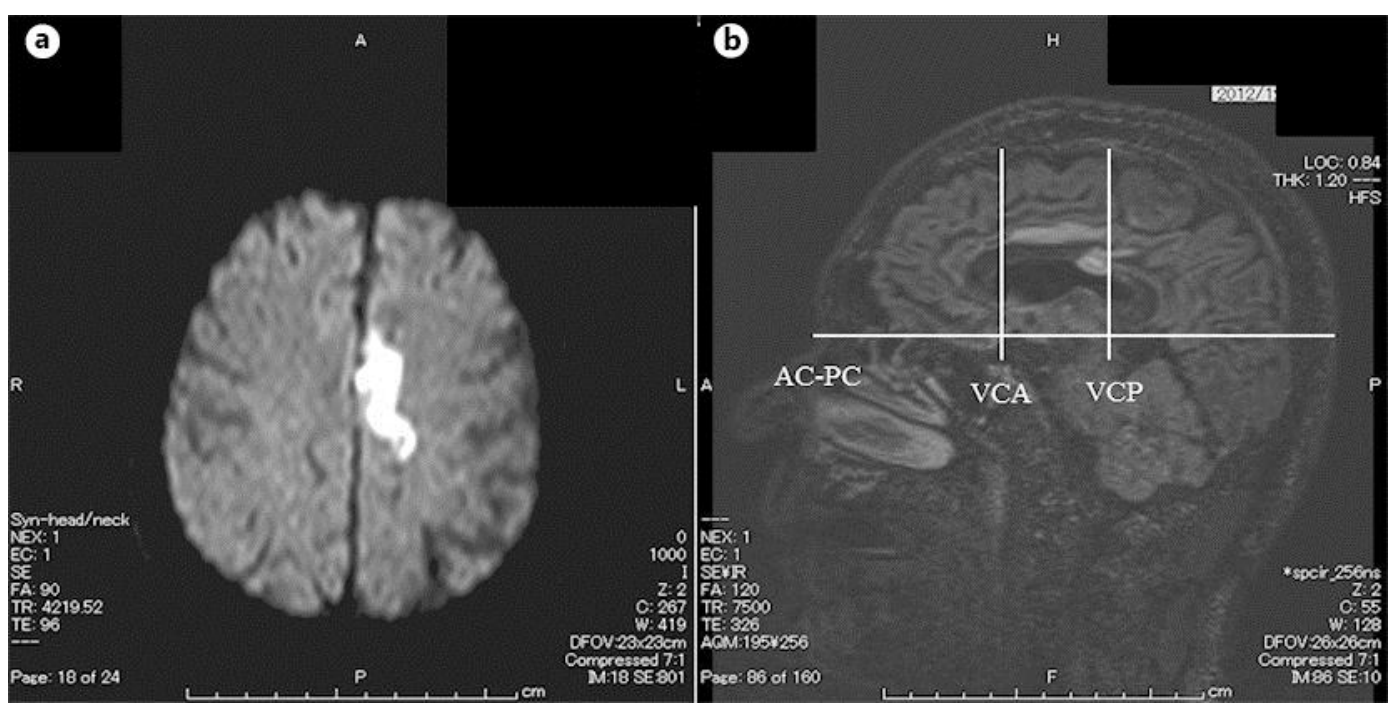

Fig. 1. a Diffusion-weighted image showing a high-intensity lesion in the medial frontal area on the left side. b Sagittal section of double inversion recovery image showing the lesion located on the cingulate gyrus between the VCA and VCP line. AC-PC = Anterior commissure-posterior commissure line. 